Research Journal of Applied Sciences 13 (2): 137-145, 2018

ISSN: $1815-932 \mathrm{X}$

(C) Medwell Journals, 2018

\title{
The Control Schemes of Vehicle Steer by Wire System by using Fuzzy Logic and PID Controller
}

${ }^{1,2}$ Mohd Zaidi Mohd Tumari, ${ }^{1}$ Muhamad Azidi Mohd Nasir, ${ }^{1}$ Shahrizal Saat,

${ }^{1}$ A. Shamsul Rahimi A. Subki, ${ }^{1}$ Wan Norhisyam Abd Rashid,

${ }^{3}$ Mohd Helmi Suid and ${ }^{3}$ Mohd Riduwan Ghazali

${ }^{1}$ Faculty of Engineering Technology,

${ }^{2}$ Centre for Robotics and Industrial Automation, Universiti Teknikal Malaysia Melaka,

Hang Tuah Jaya, 76100 Durian Tunggal, Melaka, Malaysia

${ }^{3}$ Faculty of Electrical and Electronics, Universiti Malaysia Pahang, 26600 Pekan, Pahang, Malaysia

\begin{abstract}
Recently, the Vehicle Steer-By-Wire (VSBW) system has improved significantly in terms of vehicle dynamics, comfort, safety, maneuverability and stability. VSBW eliminates the mechanical linkage between steering wheel and the front wheels which caused the practical problems for vehicle steering control. This study presents investigations into the development of PID and fuzzy logic control schemes for steering wheel returnability, directional control and wheel synchronization of a VSBW system. For PID control scheme, PD controller is used to control the returnability of steering wheel while PID controller is used to control the angle of front wheel. The Ziegler Nichols method is used for tuning the PID parameters. The fuzzy logic controller is used to control the returnability of steering wheel. The implementation environment is developed within LabView Software for comparison of performance for both control schemes. Implementation results of the response of the VSBW system with the PID and fuzzy logic controller are presented in time domains. The performances of control schemes are examined in terms of steering wheel returnability, directional control and wheel synchronization.
\end{abstract}

Key words: Vehicle-steer-by-wire, PID controller, fuzzy logic controller, performances, schemes, steering

\section{INTRODUCTION}

Conventionally, the vehicle steering method uses a mechanical connection between the steering wheel and the front wheels. Recent developments in VSBW system has become one of the major interesting research subjects due to the main characteristic which is to completely eliminate as many mechanical components (steering shaft, column, gear reduction mechanism, etc.,) as possible as shown in Fig. 1 (Cetin et al., 2010).

Despite the mechanical linkage between the steering wheel and the front wheels are removed, a VSBW system is expected to provide an advanced steering function (Fahami et al., 2012). The front wheel needs to follow the input from the driver precisely. But in the real situation, the VSBW system is faced many disturbances such as uneven condition of the road and parameter uncertainties of the system. The control approach for controlling the direction of the front wheel is a challenging task. The reliable and robust control scheme needs to be develop.

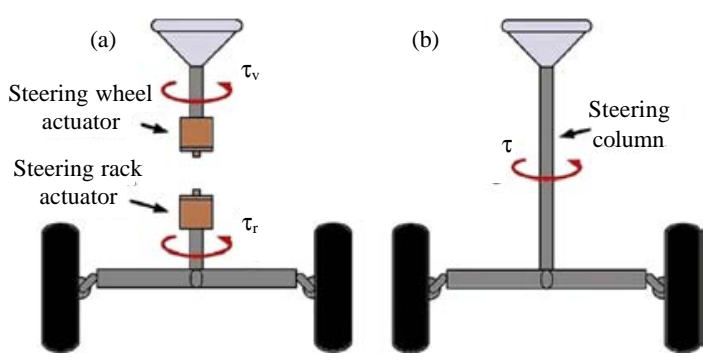

Fig. 1: a) VSBW and b) Conventional steering system (Cetin et al., 2010)

There have been several studies in the literature reporting on the modeling and control of VSBW system. The PID controller has been introduced (Fahami et al., 2012; Mohd-Tumari et al., 2016) to control the wheel synchronization. Fahami et al. (2012) also introduced a new feedforward variable steering ratio based on under propensity equation method. Mohd-Tumari et al. (2017) have introduced the PD-PID controller where the PD

Corresponding Author: Mohd Zaidi Mohd Tumari, Faculty of Engineering Technology, Universiti Teknikal Malaysia Melaka, Hang Tuah Jaya, 76100 Durian Tunggal, Melaka, Malaysia 
controller is used to control the steering wheel returnability and PID is used for directional control of front wheels. The Model Reference Control (MRC) strategy has been proposed where the measured external force/torque is used as an input to a reference model to calculate its output and the real VSBW system is controlled appropriately to track the reference system output (Cetin et al., 2012). Zheng and Anwar (2009) have proposed the yaw stability control algorithm to control the lateral and yaw motion of the vehicle by using feedback from both yaw rate and front steering angle feedback gains with respect to vehicle speed. But in this research, they used vehicle dynamics model to simulate their research which was very complicated. Another research that used vehicle dynamics model is presented (Chang, 2007). They have proposed the continuous feedback control method based on the synchronization characteristics to control the chaotic motion to improve vehicle handling and steering performance. Another method to stabilize the vehicle's yaw movement is using the virtual sensing relative to estimating the vehicle's yaw rate by only measuring the articulation angle and vehicle speed (Daher and Ivantysynova, 2014). This method can reduce sensor cost, maintenance and machine downtime. Bilateral control method of torque drive and angle feedback have been proposed (Wang et al., 2012). This method is controlling steering wheel block and steering actuator as master-slave plants by using the PID controller. Kazemi et al. (2011) have presented the control strategies of steering wheel using PID controller and Active Front Steering (AFS) controller for front wheel system. An Adaptive Sliding Mode (ASM) controller has been implemented in VSBW system that can cope with parametric uncertainties and estimate the coefficient of the self-aligning torque (Sun et al., 2016). Several attempts have been made to control the VSBW system and the system related to motor control by using fuzzy logic controller (Natsheh and Buragga, 2010; Elmi et al., 2011; Nianjiong and Qifeng, 2015). Nevertheless, the implementation of fuzzy logic controller requires a large amount of design effort to tune the membership functions.

Most of existing control schemes of VSBW system have primarily concentrated on the vehicle yaw stability which is involved deep on vehicle dynamics model. Only a few researches that focus on steering wheel model and front wheel model system (Fahami et al., 2012; Mohd-Tumari et al., 2016, 2017; Kazemi et al., 2011; Fahami et al., 2015). Fahami et al. (2012), Mohd-Tumari et al. $(2016,2017)$ they used PID controller to control the front wheel angle with existence of disturbance and torque. The proposed controller was able to reduce the disturbance error and the front wheel angle is increased and proportional to the vehicle speed. Thus, the proposed control strategy improved maneuverability and stability of the system. Fahami et al. (2015) proposed the force feedback torque control for driver steering feel by using Linear Quadratic Regulator (LQR) controller. The compensation torque is able to improve the steering feel and stabilize the VSBW system.

This study presents an investigation into the development of PID and fuzzy logic control schemes of steering wheel returnability, directional control and wheel synchronization of VSBW system. The PID controller parameters $\left(\mathrm{K}_{\mathrm{p}}, \mathrm{K}_{\mathrm{d}}, \mathrm{K}_{\mathrm{i}}\right)$ is tuned by using Ziegler Nichols method. The implementation environment is developed within LabView Software for evaluation of performance of the control schemes. The performances of control schemes are examined in terms of input tracking capability, wheel synchronization and time response specifications with the absence of disturbances.

\section{MATERIALS AND METHODS}

This study provides a brief description on the modelling of VSBW system as a basis of a simulation environment for the development and assessment of the control techniques. The VSBW system is mathematically modelled using Newton's law to derive the dynamic equation for wheel angle displacement about the kingpin axis (Ancha et al., 2007). The driver input torque, $T_{\text {driver }}$ at the steering wheel is the primary external input of the steering systems and the wheel rotational angles are the desired outputs. The distinguishing feature of the VSBW configuration is the physically decoupled driver interface and rack assembly. The torque input at the steering wheel is transmitted by means of electric signals to the rack's servo motors to obtain the desired wheel angle for vehicle directional control (Kaufmann et al., 2001). The lumped parameter of non-linear mathematical model for VSBW system is summarized in Table 1 . The dynamic equations for the steering wheel, electric actuators, rack displacement and wheel angular displacements are presented.

Steering wheel system modelling: Figure 2 shows the steering wheel diagram. In steering wheel system, the input to the system are the steering angle, $\theta_{\mathrm{sw}}$ and driver Torque, $\mathrm{T}_{\text {driver }}$. While motor torque, $\mathrm{T}_{\mathrm{M} 1}$ and Torque friction, $\mathrm{T}_{\text {fri }}$ reacted as a disturbance. The output of the system is the steering motor current, $i_{\alpha, 1}$ and steering motor angular displacement, $\theta_{\mathrm{M} 1}$. $\mathrm{B}_{\mathrm{sc}}$ is steering lumped inertia, $R_{1}$ is a motor electrical Resistance, $L_{1}$ is a motor electrical inductance, $\mathrm{I}_{\mathrm{M} 1}$ is a lumped inertia motor and $\mathrm{K}_{b 1}$ is a steering motor emf. The mathematical equations of the steering wheel system are given as follows. Steering wheel angle: 


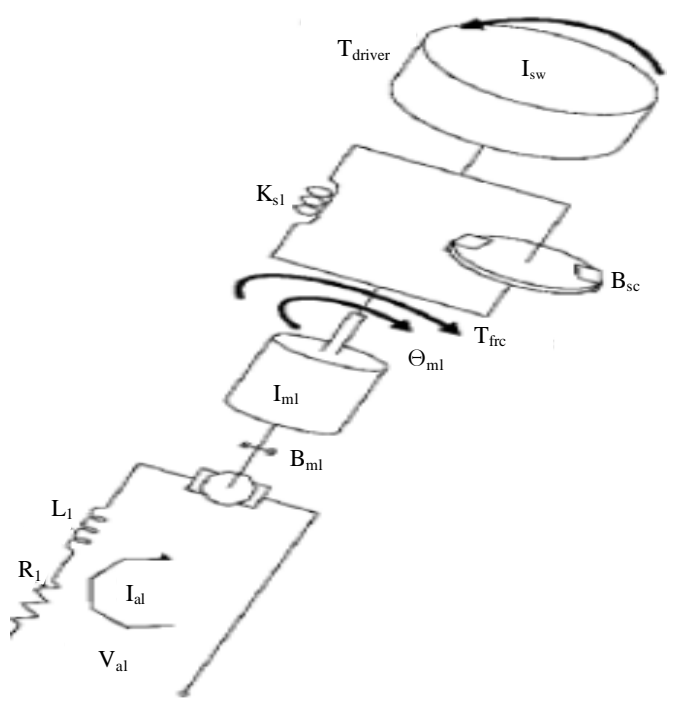

Fig. 2: Steering wheel diagram

\begin{tabular}{|c|c|c|}
\hline Parameters & Values & Units \\
\hline $\mathrm{B}_{\mathrm{kp}}$ & 30 & Nmsec/rad \\
\hline $\mathrm{B}_{\mathrm{rack}}$ & 25 & Nmsec/rad \\
\hline $\mathrm{B}_{\mathrm{sc}}$ & $13.6 \mathrm{e}-02$ & Nmsec/rad \\
\hline $\mathrm{B}_{\mathrm{mi}}$ & 1 & Nmsec/rad \\
\hline $\mathrm{B}_{\mathrm{rack}}$ & 25 & Nmsec/rad \\
\hline $\mathrm{K}_{\mathrm{si}}$ & 3500 & $\mathrm{Nm} / \mathrm{rad}$ \\
\hline $\mathrm{T}_{\mathrm{frc}}$ & Random & $\mathrm{Nm}$ \\
\hline $\mathrm{I}_{\mathrm{WW}}$ & $7.9 \mathrm{e}-03$ & $\mathrm{kgm}^{2}$ \\
\hline $\mathrm{T}_{\mathrm{M} 1}$ & Random & $\mathrm{Nm}$ \\
\hline $\mathrm{L}$ & $2 \mathrm{e}-03$ & $\mathrm{H}$ \\
\hline $\mathrm{R}_{1}$ & 4.6 & $\Omega$ \\
\hline $\mathrm{R}_{2}$ & 0.6 & $\Omega$ \\
\hline $\mathrm{k}_{\mathrm{bi}}$ & $35.3 \mathrm{e}-02$ & Vs/rad \\
\hline $\mathrm{I}_{\mathrm{M} 2}$ & 1.9 & $\mathrm{Kg} \mathrm{m}{ }^{2}$ \\
\hline$r_{p}$ & $3.5 \mathrm{e}-02$ & $\mathrm{~m}$ \\
\hline $\mathrm{r}_{\mathrm{L}}$ & 0.3 & $\mathrm{~m}$ \\
\hline $\mathrm{m}_{\mathrm{rack}}$ & 2.0 & $\mathrm{~kg}$ \\
\hline $\mathrm{k}_{\mathrm{Lf}}$ & 26000 & Nmsec/rad \\
\hline$F_{\text {frrack }}$ & 9 & $\mathrm{Nm}$ \\
\hline$\underline{T}_{f k p}$ & 2 & $\mathrm{Nm}$ \\
\hline
\end{tabular}

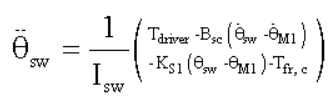

Steering motor angular displacement:

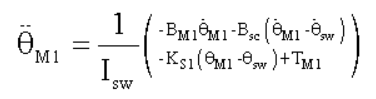

Steering motor current:

$$
\frac{\mathrm{di}_{\mathrm{a} 1}}{\mathrm{dt}}=\frac{1}{\mathrm{~L}_{1}}\left(-\mathrm{R}_{1} \mathrm{i}_{\mathrm{a} 1}-\mathrm{k}_{\mathrm{b} 1} \dot{\theta}_{\mathrm{M} 1}+\mathrm{V}_{\mathrm{s} 1}\right)
$$

Front wheels system modelling: Figure 3 shows the front wheels diagram. The steering motor angular displacement,

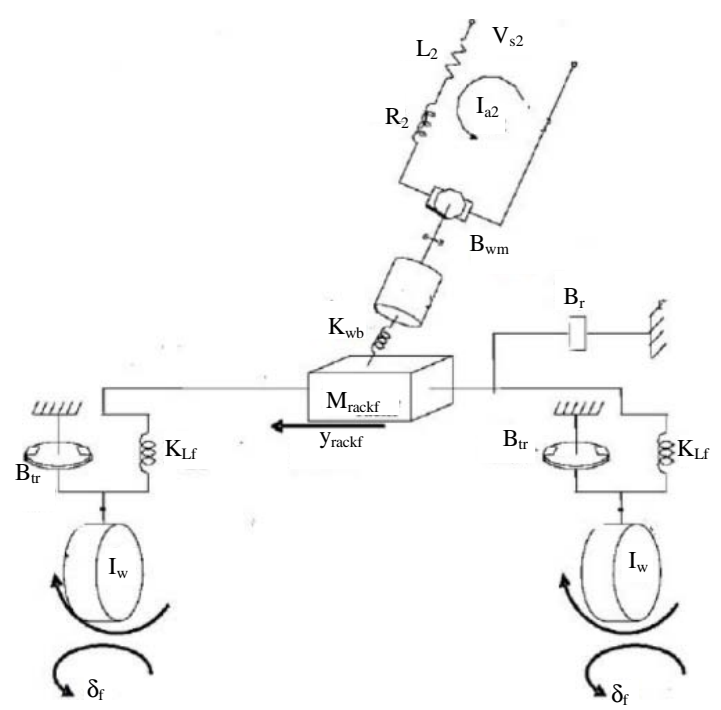

Fig. 3: Front wheels diagram

$\theta_{\mathrm{M} 1}$ is considered the input of the front wheel system. The mathematical equations of the front wheel system are written as follows. Front motor angular displacement:

$$
\ddot{\theta}_{\mathrm{M} 2}=\frac{1}{\mathrm{I}_{\mathrm{M} 2}}=\left(\begin{array}{l}
-\mathrm{E}_{\mathrm{M} 2} \dot{\theta}_{\mathrm{M} 2}-\mathrm{T}_{\mathrm{M} 2} \\
-\mathrm{K}_{\mathrm{s} 2}\left(\theta_{\mathrm{M} 2}-\mathrm{y}_{\mathrm{mad}} \mathrm{r}_{\mathrm{f}}\right)
\end{array}\right)
$$

Front motor current:

$$
\frac{\mathrm{di}_{\mathrm{a} 2}}{\mathrm{dt}}=\frac{1}{\mathrm{~L}_{2}}\left(-\mathrm{R}_{2} \mathrm{i}_{\mathrm{a} 2}-\mathrm{k}_{\mathrm{b} 2} \dot{\theta}_{\mathrm{M} 2}+\mathrm{V}_{\mathrm{S} 2}\right)
$$

Rack displacement:

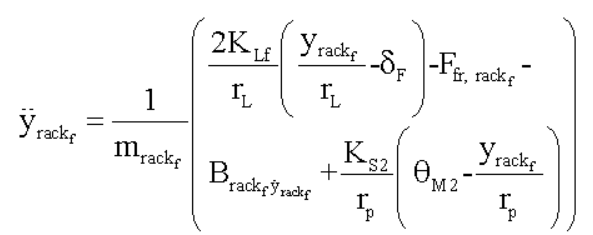

Front wheel rotational angular acceleration:

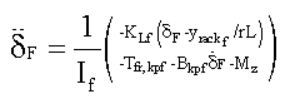

PID controller: In this study, PID control scheme for steering wheel returnability, directional control and wheel synchronization of a VSBW system is proposed. PID control has been one of the control system design method of the longest history. PID controller is mainly to adjust an appropriate proportional gain $\left(\mathrm{K}_{\mathrm{p}}\right)$ integral gain $\left(\mathrm{K}_{\mathrm{i}}\right)$ and differential gain $\left(\mathrm{K}_{d}\right)$ to achieve the optimal 
Res. J. Applied Sci., 13 (2): 137-145, 2018

Table 2: Characteristics of PID controller

\begin{tabular}{|c|c|c|c|c|}
\hline $\begin{array}{l}\text { Parameter } \\
\text { increase }\end{array}$ & $\begin{array}{l}\text { Rise } \\
\text { time }\end{array}$ & Overshoot & $\begin{array}{l}\text { Settling } \\
\text { time }\end{array}$ & $\begin{array}{l}\text { Steady-state } \\
\text { error }\end{array}$ \\
\hline & Decre & & cre & \\
\hline & Decrease & Increase & Increase & Eliminate \\
\hline & Small change & Decrease & Decrease & Small change \\
\hline
\end{tabular}

Table 3: Formula for PID tuning parameter

\begin{tabular}{llll}
\hline PD type & $\mathrm{K}_{\mathrm{p}}$ & $\mathrm{K}_{\mathrm{i}}$ & $\mathrm{K}_{\mathrm{d}}$ \\
\hline $\mathrm{P}$ & $0.5 \mathrm{~K}_{\mathrm{cr}}$ & $\infty$ & 0 \\
$\mathrm{PI}$ & $0.45 \mathrm{~K}_{c r}$ & $\mathrm{P}_{\mathrm{cr}} / 1.2$ & 0 \\
$\mathrm{PID}$ & $0.6 \mathrm{~K}_{\mathrm{cr}}$ & $1 / \mathrm{P}_{\mathrm{cr}} / 2$ & $\mathrm{P}_{\mathrm{cr}} / 8$ \\
\hline
\end{tabular}

control performance. The relationship between error e(t) and control signal $u(t)$ can be formulated in Eq. 8:

$$
\mathrm{u}(\mathrm{t})=\mathrm{K}_{\mathrm{p}} \mathrm{e}(\mathrm{t})+\mathrm{K}_{\mathrm{i}} \int_{0}^{\mathrm{t}} \mathrm{e}(\mathrm{t}) \mathrm{dt}+\mathrm{K}_{\mathrm{d}} \frac{\mathrm{de}(\mathrm{t})}{\mathrm{dt}}
$$

Table 2 shows the characteristics of PID controller. It shows the effects of system response in terms of rise time, percentage overshoot, settling time and steady state error when the parameter is increased.

Ziegler-Nichols frequency response method has been used for tuning the PID parameters. The critical gain $\left(\mathrm{K}_{\mathrm{cr}}\right)$ and the critical Period $\left(\mathrm{P}_{\mathrm{cr}}\right)$ are determined from transient response by setting the $K_{i}=8$ and $K_{d}=0$. Then, the value of $\mathrm{K}_{\mathrm{p}}$ is increased from 0 to a critical value until the step response signal oscillates with constant amplitude. The value of $K_{\text {cr }}$ is take from the first output that shows a sustained oscillation. The formula of controller tuning parameter for Ziegler-Nichols method is shown in Table 3 .

The block diagram of the VSBW system is shown in Fig. 4. The input for the system is a torque driver, $T_{\text {driver }}$. The reference is zero degree for steering wheel to return to original state. PD controller is responsible to compensate the error produced by steering wheel angle, $\theta_{s w}$. Then, $\theta_{s w}$ is fed to the input of the front wheel system. The PID controller for front wheel system will control the wheel displacement, $\delta_{\mathrm{f}}$ to operate the system according to the input.

Fuzzy logic controller: In this study, Fuzzy Logic Controller (FLC) for steering wheel returnability of a VSBW system is proposed. FLC has been widely used because this method is quite useful in terms of reliability and robustness. FLC controls a system based on mathematical systems that analyses the analog input using logical variable. This logical variable takes on continuous value between 1 and 0 defers to digital logic concept where it only operates on either true or false

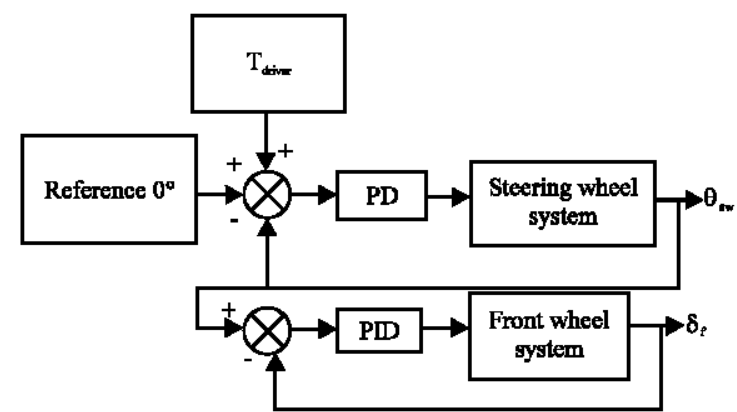

Fig. 4: Block diagram of VSBW system using PID controller

( 1 or 0 ). FLC is simple to control, low cost and the possibility to design without knowing the exact mathematical model of the system.

The process begins when FLC reads the signals from encoder and control the motor movement by considering the feedback signal as error. This process is known as fuzzification. Then, the controlled variable in FLC is sends to fill in the rules created where the process more complicated and needs expert to handle tuning to the right value. Finally, the fuzzy variable is converted to analog signal before it is send to the motor on VSBW system. This process is called defuzzification. The Center of Area $(\mathrm{COA})$ is selected as defuzzification method.

First, the FLC calculates the scale membership functions and within the range of output variable. The FLC then uses the equation to calculate the geometric of this area. The CoA effectively calculate the best compromise between multiple of output linguistic terms. Equation 9 shows the CoA formula:

$$
\operatorname{CoA}=\frac{\int_{x_{\min }}^{x_{\max }} f(x) x d x}{\int_{x_{\operatorname{man}}}^{x_{\max }} f(x) d x}
$$

Where:

$\mathrm{CoA}=$ Center of Area

$\mathrm{X}=$ The value of linguistic variable

$\mathrm{X}_{\min }$ and $\mathrm{X}_{\max }=$ The range of linguistic variable

Hardware setup: In this study, the hardware setup to implement the experiments of VSBW is presented. Figure 5 and 6 show the steering wheel and front wheel hardware, respectively. NI MyRIO is used as an interface between hardware and software. The list of components used in this project are presented in Table 4. 


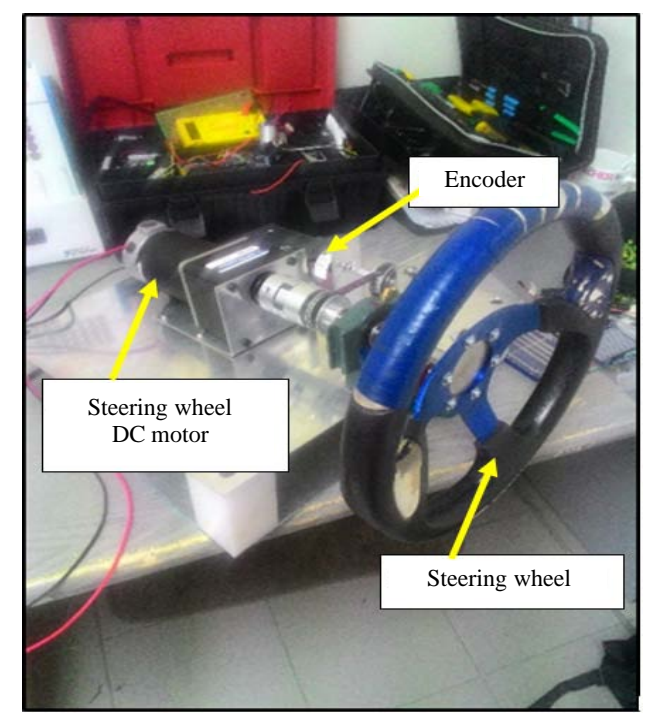

Fig. 5: Steering wheel hardware

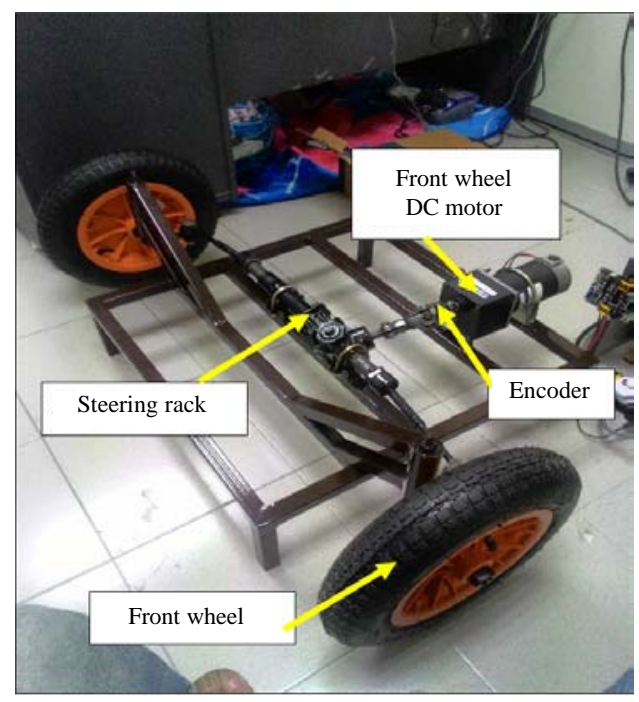

Fig. 6: Front wheel hardware

Software setup: In this study, the software setup to run the experiments of VSBW is presented. The LabView Version 2015 Software is used in this project. The LabView block diagram for software setup is shown in Fig. 7. The PID parameters for steering wheel obtained from the Ziegler Nichols method are $\mathrm{K}_{\mathrm{p}}=30$ and $\mathrm{K}_{\mathrm{d}}=0.08$ while for front wheel system are $\mathrm{K}_{\mathrm{p}}=0.02, \mathrm{~K}_{\mathrm{d}}=0.001$ and $\mathrm{K}_{\mathrm{i}}=1.06$.

The LabView block diagram of FLC is shown in Fig. 8. The program needs to retrieve the rules from the tuning.fs file. The reference zero and error are used as input variables while the steering wheel angle as an output variable. One membership function is
Table 4: List of components

\begin{tabular}{ll}
\hline Items & Specifications \\
\hline DC brush motor & $7.2 \mathrm{~A}, 24 \mathrm{~V}, 120 \mathrm{~W}$ \\
DC motor driver & $5-30 \mathrm{~V}, 30 \mathrm{~A}$ \\
Rotary encoder & $5-24 \mathrm{~V}, 500 \mathrm{P} / \mathrm{R}$ \\
NI MyRio & Xilinx z-7010,667 MHz \\
\hline
\end{tabular}

Table 5: Range of membership function of error

\begin{tabular}{lll}
$\begin{array}{l}\text { Name of } \\
\text { membership (error) }\end{array}$ & $\begin{array}{l}\text { Type of } \\
\text { membership } \\
\text { (shape) }\end{array}$ & $\begin{array}{l}\text { Parameter of } \\
\text { membership function } \\
\text { (numerical range) }\end{array}$ \\
\hline Large Negative (LN) & Triangle & $-800-800-500$ \\
Medium Negative (MN) & Triangle & $-600-450-300$ \\
Small Negative (SN) & Triangle & $-400-200-0$ \\
Zero (Z) & Triangle & $-150-0-150$ \\
Small Positive (SP) & Triangle & $0-200-400$ \\
Medium Positive (MP) & Triangle & $300-450-600$ \\
Large Positive (LP) & Triangle & $500-800-800$ \\
\hline
\end{tabular}

Table 6: Range of membership function of output variable

\begin{tabular}{lll}
$\begin{array}{l}\text { Name of membership } \\
\text { (angle) }\end{array}$ & $\begin{array}{l}\text { Type of } \\
\text { membership } \\
\text { (shape) }\end{array}$ & $\begin{array}{l}\text { Parameter of } \\
\text { membership function } \\
\text { (numerical range) }\end{array}$ \\
\hline Large Negative (LN) & $\begin{array}{l}\text { Triangle } \\
\text { Medium Negative (MN) }\end{array}$ & $\begin{array}{l}\text { Triangle } \\
\text { Triangle }\end{array}$ \\
Small Negative (SN) & $-70-50-60$ \\
Zero (Z) & Triangle & $-40-20-0$ \\
Small Positive (SP) & Triangle & $0-20-0-20$ \\
Medium Positive (MP) & Triangle & $30-50-70$ \\
Large Positive (LP) & Triangle & $60-90-90$ \\
\hline
\end{tabular}

used for reference zero input and the trapezoid shape is selected with numerical range between -2 and 2 . For error, seven membership functions are used and triangle shape is selected as shown in Fig. 9. The range of error membership functions is shown in Table 5.

Seven membership functions are used for output variables and Triangle shape is selected as shown in Fig. 10. The range of output membership functions is shown in Table 6. The FLC is designed with seven rules as a closed loop component of the control strategy for reducing the steering wheel error of VSBW system. The rule of FLC is shown in are:

- If 'error' is 'LN' and 'Input' is 'zero' Then 'angle' is 'LN'

- If 'error' is ' $\mathrm{MN}$ ' and 'Input' is 'zero' Then 'angle' is 'MN'

- If 'error' is ' $\mathrm{SN}$ ' and 'Input' is 'zero' Then 'angle' is 'SN'

- If 'error' is 'zero' and 'Input' is 'zero' Then 'angle' is 'zero'

- If 'error' is 'SP' and 'Input' is 'zero' Then 'angle' is 'SP'

- If 'error' is 'MP' and 'Input' is 'zero' Then 'angle' is 'MP'

- If 'error' is 'LP' and 'Input' is 'zero' Then 'angle' is 'LP' 
Res. J. Applied Sci., 13 (2): 137-145, 2018

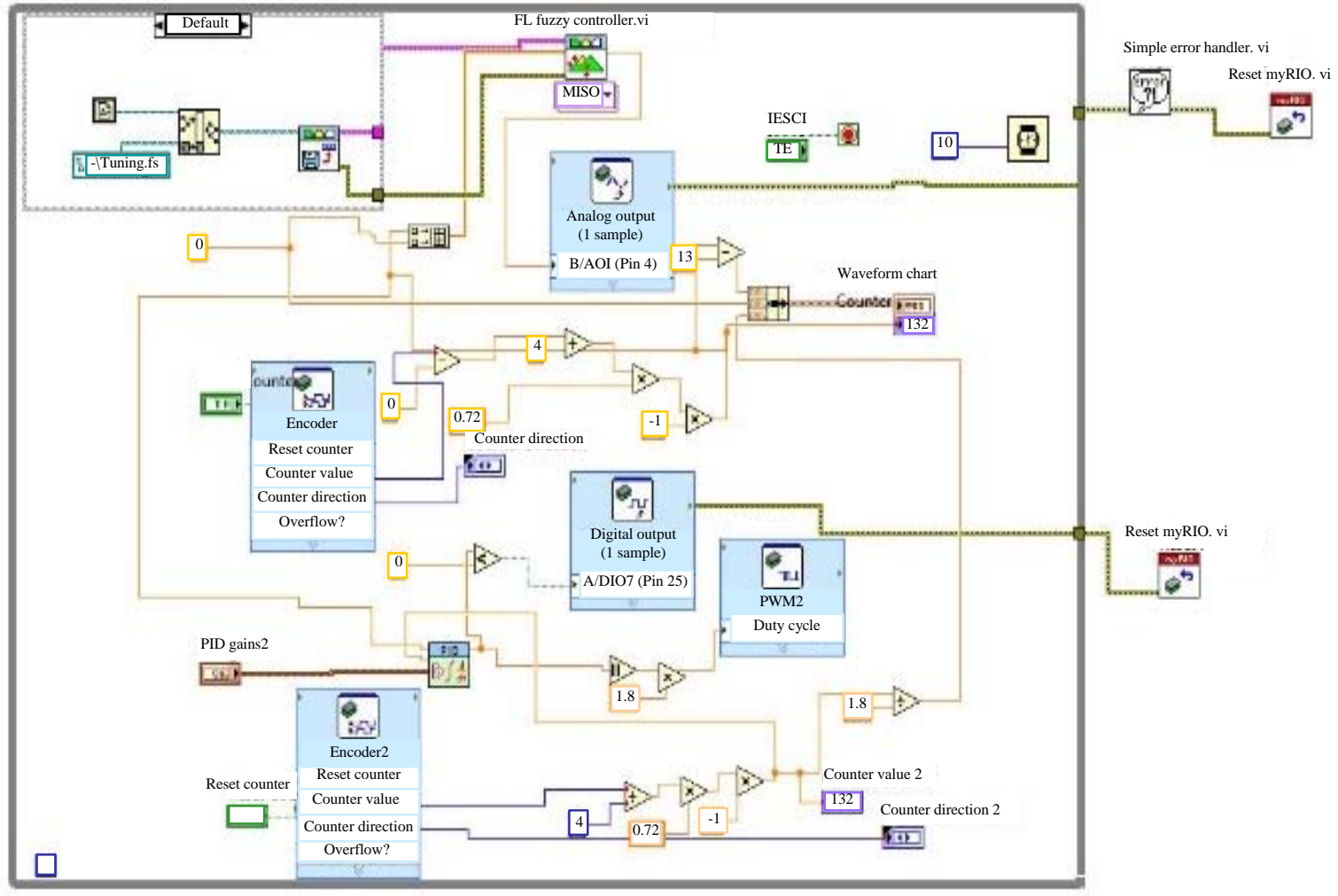

Fig. 7: LabView block diagram for software setup

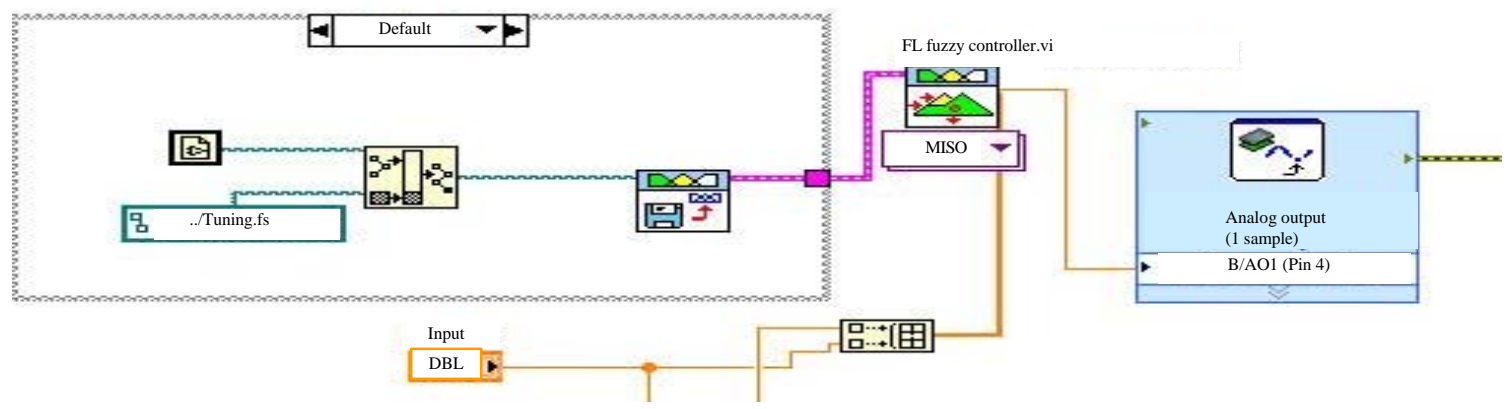

Fig. 8: Fuzzy logic controller block diagram in LabView
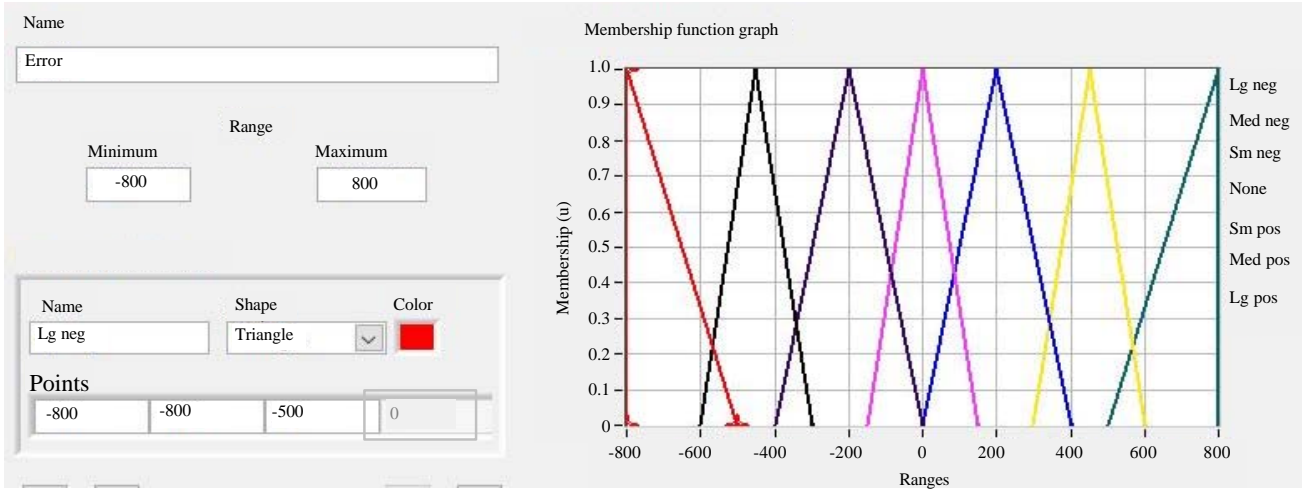

Fig. 9: Membership functions of error 
Res. J. Applied Sci., 13 (2): 137-145, 2018

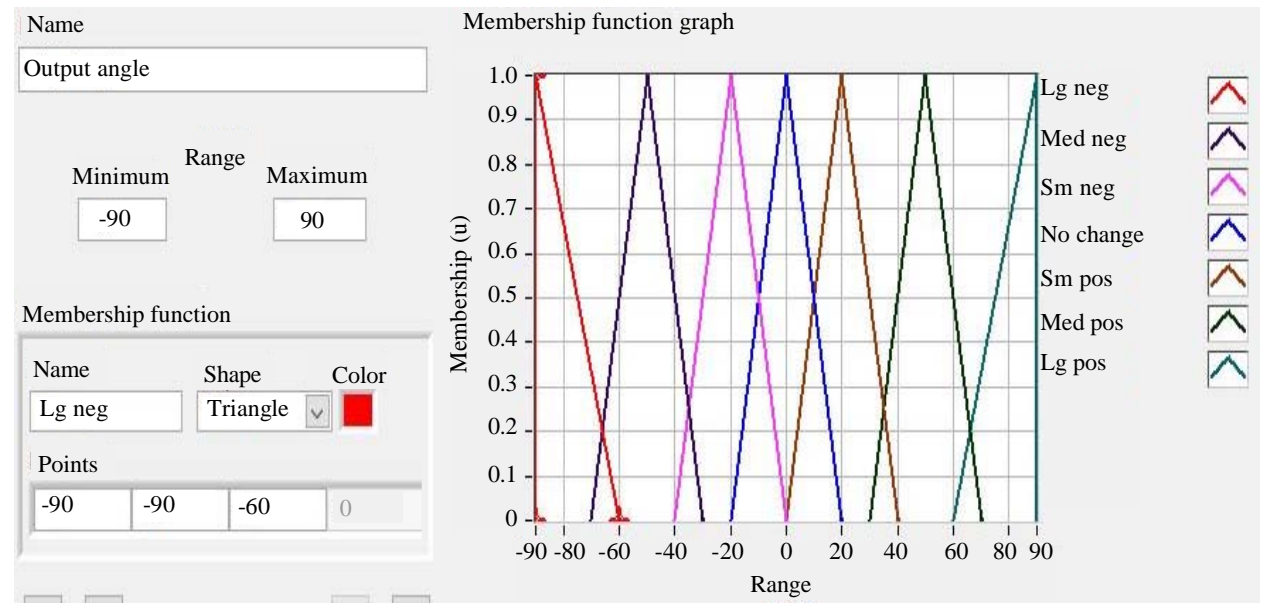

Fig. 10: Membership functions of output variable

\section{RESULTS AND DISCUSSION}

In this study, the experiment results of the PID controller and FLC have been tested on the VSBW hardware and the corresponding results are presented. The performances of the control schemes are assessed in terms of steering wheel returnability, directional control and wheel synchronization. Figure 11 shows the step response of VSBW system by using PID controller. The reference value of step input is $200^{\circ}$. The time is in centisecond $\left(10^{-2} \mathrm{sec}\right)$. The results shows the steering wheel is able to track the input with no overshoot and no steady state error. The rise time for steering wheel response is $0.3 \mathrm{sec}$ while the settling time is $0.6 \mathrm{sec}$. From this step response we can see that the front wheel angle follows the steering wheel angle accordingly with a little delay. The rise time for front wheel angle is $0.4 \mathrm{sec}$ while the settling time is $0.75 \mathrm{sec}$. As we can see, the front wheel system is delayed approximately $0.15 \mathrm{sec}$ to synchronize with steering wheel angle.

Figure 12 shows the response of steering wheel to return to zero degree and the front wheel to follow steering wheel angle with PID controller. It shows the response of front wheel when the steering wheel is being rotate and hold for a certain time. The reference is zero degree which means the steering wheel needs to return to its original state. Firstly, the steering wheel is being rotated clockwise to $50^{\circ}$ for $7 \mathrm{sec}$. Then, the steering wheel has been released. The result shows that the steering wheel was able to return to $0^{\circ}$ with zero steady state error and no overshoot. This signal has no peak time, the rise time of this system is $1.4 \mathrm{sec}$ and it takes about $2.4 \mathrm{sec}$ to settle. Secondly, the steering wheel is being rotated counter-clockwise to $100^{\circ}$ for $4 \mathrm{sec}$.
Table 7: The summarize results for PID and FLC

\begin{tabular}{lccccc}
\hline Controller & $\begin{array}{c}\text { Test angle } \\
\left({ }^{\circ}\right)\end{array}$ & $\begin{array}{c}\text { Rise time } \\
(\mathrm{sec})\end{array}$ & $\begin{array}{c}\text { Settling } \\
\text { time }(\mathrm{sec})\end{array}$ & Overshoot & $\begin{array}{c}\text { Steady state } \\
\text { error }\end{array}$ \\
\hline PID & 50 & 1.4 & 2.4 & 0 & 0 \\
& -100 & 2.2 & 3.0 & 0 & 0 \\
FLC & 150 & 0.7 & 1.5 & 0 & 0 \\
& 350 & 1.4 & 2.6 & 0 & 0 \\
& 100 & 0.9 & 1.1 & 0 & 0 \\
\hline
\end{tabular}

Then, the steering wheel has been released. The result shows that the steering wheel was able to return to zero degree with zero steady state error and no overshoot. This signal has no peak time, the rise time of this system is $2.2 \mathrm{sec}$ and it takes about $3 \mathrm{sec}$ to settle. It is clearly shows that the steering wheel of VSBW system has obtain the returnability as the conventional steering wheel system. The result also shows that the front wheel was successfully follows the angle of steering wheel with little error.

For FLC, the VSBW system is tested for steering wheel returnability. The steering wheel returnability response with FLC is shown in Fig. 13. The steering wheel is tested for three different angles which are 150, 350 and $100^{\circ}$ in clockwise direction. For $150^{\circ}$, no overshoot and steady error while the rise time is $0.7 \mathrm{sec}$ settling time is $1.5 \mathrm{sec}$. For $350^{\circ}$, also no overshoot and steady error while the rise time is $1.4 \mathrm{sec}$ and settling time is $2.6 \mathrm{sec}$. For $100^{\circ}$, also no overshoot and steady error while the rise time is $0.9 \mathrm{sec}$ and settling time is $1.1 \mathrm{sec}$.

In comparison with PID controller, the FLC is produced a better results with faster rise time and faster settling time in terms of steering wheel returnability. The comparison between PID and FLC is summarized in Table 7. 
Res. J. Applied Sci., 13 (2): 137-145, 2018

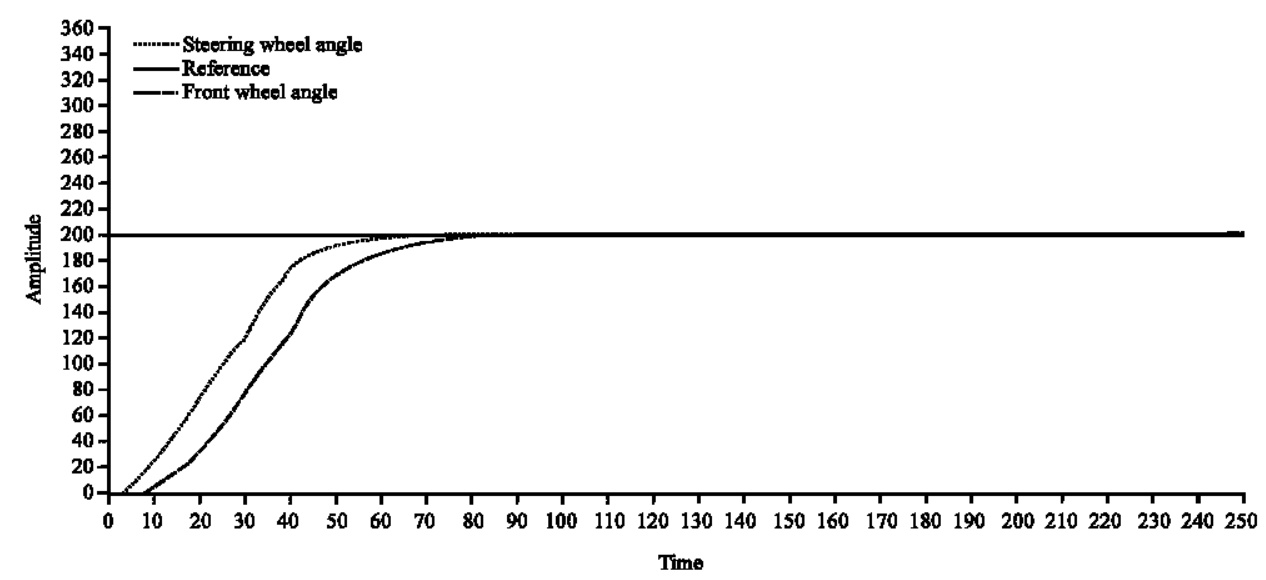

Fig. 11: The step response of VSBW system with PID controller

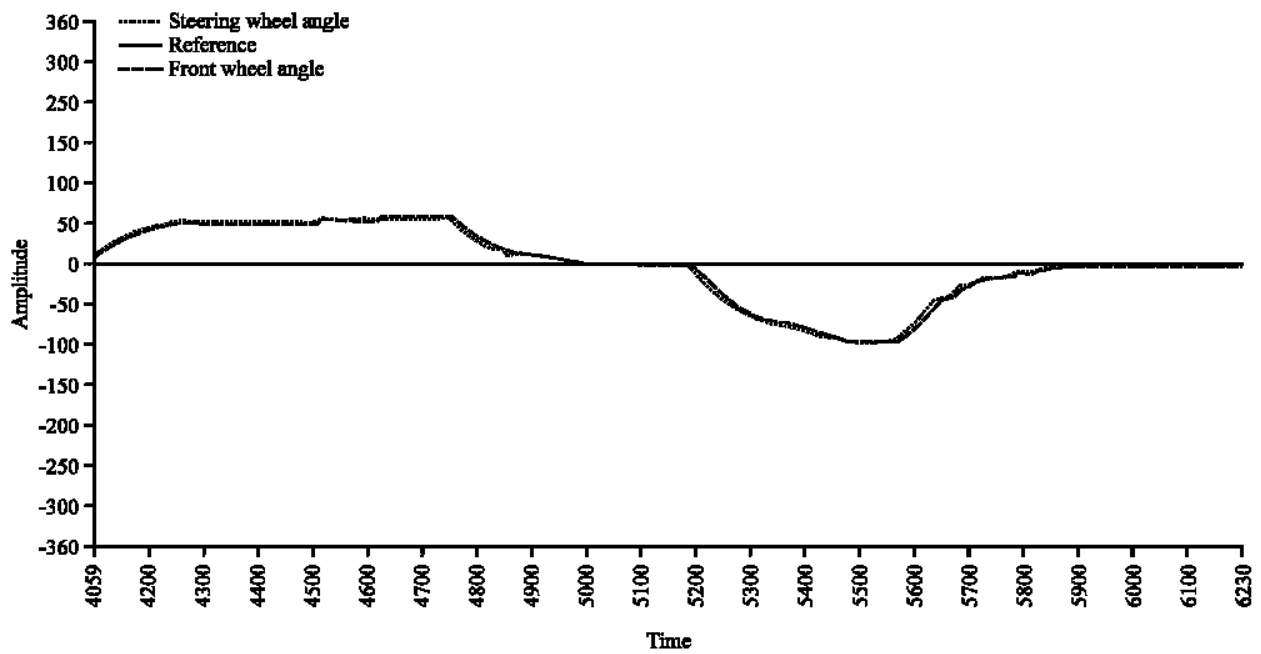

Fig. 12: The response of VSBW with PID controller

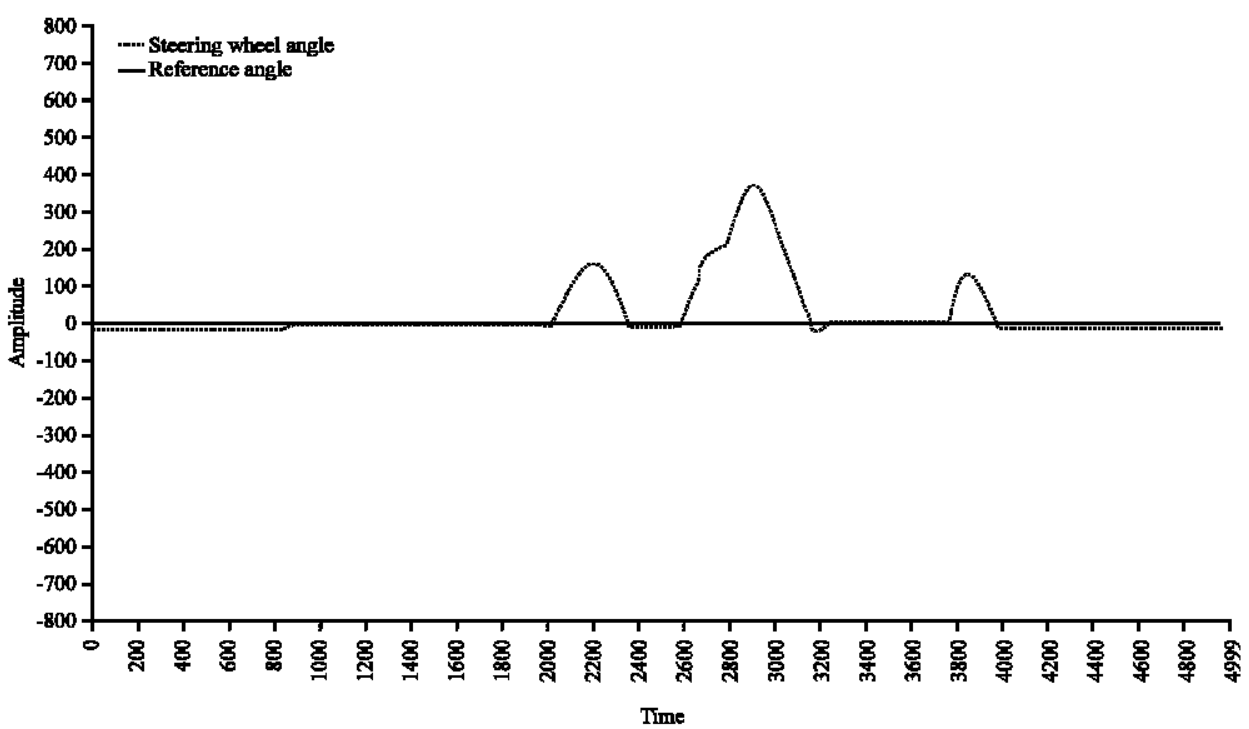

Fig. 13: The response of steering wheel returnability with FLC 


\section{CONCLUSION}

Investigations into steering wheel returnability, directional control and wheel synchronization of a VSBW system using the PID controller and FLC have been presented. The proposed control schemes have been implemented and tested within experimental environment of a VSBW system. The performances of the control schemes have been evaluated in time response specifications. FLC is better than PID controller in terms of steering wheel returnability. Nevertheless, the implementation of PID controller and FLC requires alarge amount of design effort to achieve the better performance. Finally, it is concluding that the PID controller and FLC is capable to improve the performance of VSBW system.

\section{ACKNOWLEDGEMENT}

This research was supported by Faculty of Engineering Technology, Universiti Teknikal Malaysia Melaka, especially, Robotic industrial and Automation (RIA) Research Group under research grant PJP/2015/FTK (21C)/S01441.

\section{REFERENCES}

Ancha, S., A. Baviskar, J.R. Wagner and D.M. Dawson, 2007. Ground vehicle steering systems: Modelling, control and analysis of hydraulic, electric and steer-by-wire configurations. Intl. J. Veh. Des., 44: 188-208.

Cetin, A.E., M.A. Adli, D.E. Barkana and H. Kucuk, 2010. Implementation and development of an adaptive steering-control system. IEEE. Trans. Veh. Technol., 59: 75-83.

Cetin, A.E., M.A. Adli, D.E. Barkana and H. Kucuk, 2012. Adaptive on-line parameter identification of a steer-by-wire system. Mechatron., 22: 152-166.

Chang, S.C., 2007. Synchronization in a steer-by-wire vehicle dynamic system. Intl. J. Eng. Sci., 45: 628-643.

Daher, N. and M. Ivantysynova, 2014. A virtual yaw rate sensor for articulated vehicles featuring novel electro-hydraulic steer-by-wire technology. Control Eng. Pract., 30: 45-54.

Elmi, N., B. Samadi and A. Ohadi, 2011. Handling safety improvement for steer-by-wire vehicle using fuzzy controller. Proceedings of the 2nd International Conference on Control, Instrumentation and Automation(ICCIA'11), December 27-29, 2011, IEEE, Shiraz, Iran, ISBN:978-1-4673-1689-7, pp: 144-149.

Fahami, S.M.H., H. Zamzuri and S.A. Mazlan, 2015. Development of estimation force feedback torque control algorithm for driver steering feel in vehicle steer by wire system: Hardware in the loop. Intl. J. Veh. Technol., 2015: 1-17.
Fahami, S.M.H., H. Zamzuri, S.A. Mazlan and M.A. Zakaria, 2012. Modeling and simulation of vehicle steer by wire system. Proceedings of the 2012 IEEE Symposium on Humanities, Science and Engineering Research(SHUSER'12), June 24-27, 2012, IEEE, Kuala Lumpur, Malaysia, ISBN:978-1-4673-1311-7, pp: 765-770

Kaufmann, T., S. Millsap, B. Murray and J. Petrowski, 2001. Development Experience with Steer-by-Wire (No. 2001-01-2479). SAE International, Warrendale, Pennsylvania,

Kazemi, R., I. Mousavinejad, I. Kish, M. Raf' at and M.B. Khaknejad, 2011. Yaw moment control of the passenger car via steer by wire system. Proceedings of the 2011 ASME-International Conference on Mechanical Engneering Congress and Exposition (IMECE'11), November 11-17, 2011, Hyatt Regency Denver at the Colorado Convention Center, Denver, Colorado, pp: 124-129.

Mohd-Tumari, M.Z., M.A.M. Nasir, M.S. Saealal, A.W.A. Aziz and S. Saat et al., 2017. The control scheme of vehicle steer by wire system by using PD-PD controller. Proceedings of the Conference on Mechanical Engineering Research Day (MERD'17), February 01-March 30, 2017, Universiti Teknikal Malaysia Melaka, Durian Tunggal, Malaysia, pp: 1-2.

Mohd-Tumari, M.Z., M.S. Saealal, W.N.A. Rashid, S. Saat and M.A.M. Nasir, 2016. The vehicle steer by wire control system by implementing PID controller. Proceedings of the 5th International Conference on Design and Concurrent Engineering (IDECON'16), September 19-20, 2016, Adya Hotel Langkawi, Kedah, Malaysia, pp: 62-68.

Natsheh, E. and K.A. Buragga, 2010. Comparison between conventional and fuzzy logic PID controllers for controlling DC motors. Intl. J. Comput. Sci. Issues, 7 : 128-134.

Nianjiong, Y. and L. Qifeng, 2015. Design and simulation for steer-by-wire system based on fuzzy-PID. Proceedings of the 7 th International Conference on Intelligent Human-Machine Systems and Cybernetics (IHMSC'15) Vol. 1, August 26-27, 2015, IEEE, Hangzhou, China, ISBN:978-1-4799-8645-3, pp: 291-294.

Sun, Z., J. Zheng, Z. Man and H. Wang, 2016. Robust control of a vehicle steer-by-wire system using adaptive sliding mode. IEEE. Trans. Ind. Electron., 63: 2251-2262.

Wang, X., C. Zong, H. Xing and R. Hu, 2012. Bilateral control method of torque drive-angle feedback used for steer-by-wire system. SAE. Intl. J. Passenger Cars-Electron. Electr. Syst., 5: 479-485.

Zheng, B. and S. Anwar, 2009. Yaw stability control of a steer-by-wire equipped vehicle via active front wheel steering. Mechatronics, 19: 799-804. 